\title{
Auditory brainstem function in women with vestibular migraine: a controlled study
}

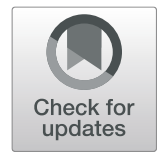

\author{
Alice A. Takeuti ${ }^{*}$ D , Mariana L. Fávero², Erica Helena Zaia ${ }^{3}$ and Fernando F. Ganança ${ }^{1}$
}

\begin{abstract}
Background: Vestibular migraine (VM) has been recognized as a diagnostic entity over the past three decades. It affects up to $1 \%$ of the general population and $7 \%$ of patients seen in dizziness clinics. It is still underdiagnosed; consequently, it is important to conduct clinical studies that address diagnostic indicators of VM. The aim of this study was to assess auditory brainstem function in women with vestibular migraine using electrophysiological testing, contralateral acoustic reflex and loudness discomfort level.

Methods: The study group consisted of 29 women with vestibular migraine in the interictal period, and the control group comprised 25 healthy women. Auditory brainstem response, frequency following response, binaural interaction component and assessment of contralateral efferent suppression were performed. The threshold of loudness discomfort and the contralateral acoustic reflex were also investigated. The results were compared between the groups.

Results: There was a statistically significant difference between the groups in the frequency following response and the loudness discomfort level.

Conclusions: The current study suggested that temporal auditory processing and loudness discomfort levels are altered in VM patients during the interictal period, indicating that these measures may be useful as diagnostic criteria.
\end{abstract}

Keywords: Migraine, Vertigo, Auditory evoked potentials, Brainstem, Hyperacusis

\section{Background}

The link between vestibular symptoms and migraine has led to the publication of diagnostic criteria for a new disorder called vestibular migraine [1-3]. Although there is a high frequency of auditory symptoms associated with migraine, there is inadequate information regarding how migraine occurs; vestibular assessments performed via hearing tests do not provide enough specific data. Psychoacoustic evaluations are normal in most cases despite reports of hearing loss in cases of acute migraine and vestibular migraine; this hearing loss is most likely as a result of cochlear vasospasms [3-8].

Specific auditory symptoms such as phonophobia (vestibular migraine and migraine without aura diagnosis criteria) and hearing loss and tinnitus (brainstem migraine with aura diagnosis criteria) suggest impairment of auditory pathways in migraine cases [2].

\footnotetext{
*Correspondence: a.takeuti@unifesp.br; aatakeuti@gmail.com

${ }^{1}$ Departamento de Otorrinolaringologia e Cirurgia de Cabeça e Pescoço,

Universidade Federal de São Paulo, São Paulo, Brazil

Full list of author information is available at the end of the article
}

Auditory brainstem responses (afferent and efferent, electric conduction, binaural interaction, temporal processing and evoked potential suppression by efferent auditory system) can be assessed with electrophysiological exams such as auditory brainstem response, binaural interaction component, frequency following response and assessments of efferent pathways by suppression of auditory brainstem responses.

Brainstem electric disorders can also affect the stapedius muscle reflex or the acoustic reflex due to dysfunctions of higher auditory centers or supratentorial structures $[9,10]$.

The aim of this study is to assess auditory brainstem function in women with vestibular migraine by means of electrophysiological testing and acoustic reflex thresholds and to verify the presence of hyperacusis according to loudness discomfort level, as defined by Nields et al. [11]. The hypothesis of this study is that women with vestibular migraine have altered auditory brainstem function due to the relationship between the trigeminovascular system and central and peripheral auditory structures.

(c) The Author(s). 2019 Open Access This article is distributed under the terms of the Creative Commons Attribution 4.0 International License (http://creativecommons.org/licenses/by/4.0/), which permits unrestricted use, distribution, and 


\section{Methods}

\section{Patients}

This case-control study enrolled 29 women with vestibular migraine (diagnosed according to the criteria of Neuhauser et al., modified by the Bárány Society and International Headache Society [2] and by the 3rd edition of The International Classification of Headache Disorders [12]) in the study group during the interictal period of vestibular migraine. The control group comprised 25 healthy women matched to the study group by age. The subjects in the study group were recruited from the vestibular migraine outpatient clinic of a neurotology service and represent all patients who fulfilled the inclusion criteria during the collection period. The control group subjects were volunteers.

All participants were screened for normal hearing (i.e., $\leq 25 \mathrm{~dB} \mathrm{HL}$ at octave frequencies from 250 to $8000 \mathrm{~Hz}$ ) and normal middle ear function (i.e., no history of chronic ear disease, normal otoscopy and normal $226 \mathrm{~Hz}$ tympanometry). To avoid any unintentional bias regarding the interictal period, a new interview was conducted to confirm the absence of current symptoms before tests.

The exclusion criteria, for both groups, were acute or chronic neurological, neurotological (other than vestibular migraine in the study group), or psychiatric disorders and/or the use of migraine prophylactic drugs, central nervous system-active drugs or contraceptives.

The procedures used in this study were approved by the ethical committee (no. 43437015.2.0000.5505). All subjects in this study agreed to and signed the informed consent form.

\section{Evoked potentials acquisition}

Electrophysiologic tests were conducted using the Intelligent Hearing System (Smart EP windows USB version 3.91) with insert earphones ER-3A. Responses were collected with silver chloride electrodes and were differentially recorded from $\mathrm{Cz}$ (active) to the ipsilateral mastoid (reference), with a common grounding electrode placed on the forehead. The subjects were instructed to lie comfortably in the supine position and relax to promote a passive recording condition. No other stimulus was used during the tests.

\section{Frequency following response recording}

The frequency following response was evoked by 1024 sweeps and $60 \mathrm{dBHL}$ tone bursts at $500 \mathrm{~Hz}$ using rarefaction polarity, with a $5000 \mu$ sise and fall time in a trapezoidal envelope and a $15,000-\mu$ s duration at a rate of 5.1 per sec. The response was filtered between 30 and $3000 \mathrm{~Hz}$ in a graduated analysis window of $50 \mathrm{msec}$. The response cycles obtained for the study group were compared to those obtained for the control group.

Auditory brainstem response recording.
The auditory brainstem response was evoked by 1024 clicks with a 100- $\mu$ s duration using a rarefaction polarity and a rate of 37.1 clicks per sec. A high-pass filter of $100 \mathrm{~Hz}$ and a low-pass filter of $3000 \mathrm{~Hz}$ were used on a 12.5-msec graduated window of analysis. Waveforms were obtained in both ears at $70 \mathrm{dBHL}$, and waves I, III and $\mathrm{V}$ were identified. The absolute latencies of waves I, III and V and interpeak latencies I-III, III-V and I-V were obtained and compared between the study group and control group.

\section{Auditory brainstem response suppression recording}

To assess the suppression of the auditory brainstem response by the efferent pathway, a $60-\mathrm{dBHL}$ intensity white noise was used in the contralateral ear (Matas et al., 2010). Waveforms were obtained at $70 \mathrm{dBHL}$ in the following order:

a) Right ear response without contralateral noise;

b) Right ear response with contralateral noise;

c) Left ear response without contralateral noise;

d) Left ear response with contralateral noise;

The absolute latencies for waves I, III and V and the interpeak I-III, III-V and I-V latencies without noise were subtracted from the results with contralateral noise, and the results were compared between the groups. The right and left ear results for the study group individuals were compared with the right and left ear results for the control group individuals, respectively.

\section{Binaural interaction component recording}

The binaural interaction component test was evoked by 1024 sweeps of $100 \mu$ s clicks with rarefaction polarity at $70 \mathrm{dBHL}$ and a rate of 37.1 stimuli per sec. A high-pass filter of $100 \mathrm{~Hz}$ and a low-pass filter of $3000 \mathrm{~Hz}$ were used for simultaneous unilateral and bilateral recording within a graduated analysis window of $12.5 \mathrm{msec}$. Three recordings were obtained:

a) Monoaural right ear stimulation and right ear potential recording;

b) Monoaural left ear stimulation and left ear potential recording;

c) Binaural stimulation and right and left ear potential recording.

The binaural interaction component trace was obtained by the sum of the monoaural recording (1 and 2) followed by the subtraction of the binaural recording [3]: (right ear + left ear) - binaural. These analyses were performed using a tool in the IHS system. The latency and amplitude of the binaural interaction component 
waveform were compared between the study group and the control group.

\section{Loudness discomfort level assessment}

Loudness discomfort levels were obtained for pure tones between 0.25 and $8 \mathrm{kHz}$ in both ears using an AC33 Interacoustics ${ }^{\circ}$ audiometer. The initial presentation level was $50 \mathrm{dBHL}$, and each stimulus was presented for approximately $2 \mathrm{~s}$, with 1 -s intervals between presentations. The presentation level was increased gradually by 5 dBHL until a discomfort sensation was evoked. The participants were instructed to raise their hands when they experienced minimal discomfort, at which point the presentations were interrupted [13].

The loudness discomfort level values were used to determine the hyperacusis level: negative (discomfort at $95 \mathrm{dBHL}$ or more at all frequencies), mild (discomfort level between 80 and $90 \mathrm{dBHL}$ at two or more frequencies), moderate (discomfort level between 65 and $75 \mathrm{dBHL}$ at two or more frequencies), and severe (discomfort level at $60 \mathrm{dBHL}$ or less at two or more frequencies) [14].

\section{Contralateral acoustic reflex assessment}

Contralateral acoustic reflex testing was performed at 500, 1000, 2000 and $4000 \mathrm{~Hz}$ for each ear in both groups using AT235 Interacoustics ${ }^{\circ}$ equipment, with pure tone presentations lasting $1.5 \mathrm{~s}$. Each stimulus was presented for $1.5 \mathrm{~s}$ at an initial intensity of $70 \mathrm{dBHL}$ and was increased by 5 -dBHL steps until the acoustic reflex was obtained. The reflex was considered absent when no response was obtained at $110 \mathrm{dBHL}$. Recruitment was defined as a difference of less than $75 \mathrm{dBHL}$ between the acoustic reflex threshold and the hearing threshold at each frequency.

\section{Data analysis}

The main researcher used Microsoft Excel 2011 was used to record and store the data. A descriptive analysis of the data that considered absolute and relative frequencies, central tendency measures (average and median) and dispersion measures (standard deviation, minimum and maximum values) was performed.

For quantitative variables, the standard distribution was verified, and Student's t-test was used to compare the groups. The equality of variance (standard deviation square) was not assumed when the homogeneity of a certain variable could not be confirmed. For the association analyses between independent qualitative variables and outcome measures, the chi-square test was used. For statistical significance, a descriptive level of 5\% $(p<0.05)$ was considered. Data were entered in Excel and analyzed with the Statistical Package for the Social Sciences (SPSS), version 22.0 for Windows.

\section{Results}

In this study, 54 women were analyzed (25 in the control group and 29 in the study group). Their ages ranged from 23 to 74 years, with an average of 49.7 years $(\mathrm{SD}=$ 13.1) and a median of 49 . There was no statistically significant difference in age between the groups $(p=0.573)$.

There was no statistically significant difference between the average latency and amplitude of binaural interaction component values when the study group and the control group were compared. The same finding was observed for the absolute and interpeak latencies obtained for the auditory brainstem response and auditory brainstem response suppression $(p>0.05)$.

The frequency following response latencies of the study group had average values that were significantly higher than those of the control group in both ears $(p<0.05)$, except for the latency of wave I in the left ear $(p=0.102)$. The frequency following response interpeak I-III variable in the left ear differed significantly between the groups $(p=0.003)$. The average for the study group was $2.00 \mathrm{msec}(\mathrm{SD}=4.1)$, while the average for the control group was $1.6 \mathrm{msec}(\mathrm{SD}=$ 0.52) (Table 1).

There was a statistically significant difference in the average loudness discomfort level threshold of the right ear between the groups at $250 \mathrm{~Hz}(p=0.006), 500 \mathrm{~Hz}$ $(p=0.013)$ and $3000 \mathrm{~Hz}(p=0.023)$. When analyzing the left ear, significant differences between groups were noted for the frequencies of $500 \mathrm{~Hz}(p=0.02), 1000 \mathrm{~Hz}(p=$ $0.014), 2000 \mathrm{~Hz}(\mathrm{p}=0.01)$ and $3000 \mathrm{~Hz}(\mathrm{p}=0.02)$, with higher levels obtained for the control group (Table 2).

When analyzing the loudness discomfort level classification, statistically significant differences were observed for both the right and left ears. For the right ear, women with mild hyperacusis tended to be more likely to be in the study group than in the control group (52\% versus $18 \% ; p=0.019)$. This tendency was verified in the left ear $(p=0.039)$ (Table 3).

For the acoustic reflex threshold, there was no significant difference between the study group and the control group $(p>0.05)$.

\section{Discussion}

In the current research, patients with vestibular migraine presented increased latencies of the frequency following response and lower discomfort thresholds compared to the control group, and the differences were statistically significant. These findings suggest altered pure tone temporal processing and mild level hyperacusis [11], respectively.

These results suggest that the trigeminovascular system has an important influence on auditory brainstem function, even in the interictal period of vestibular migraine, when the data were collected; this finding 
Table 1 Frequency Following Response latencies in the control group and study group

\begin{tabular}{|c|c|c|c|c|c|c|c|}
\hline & \multicolumn{3}{|l|}{$C G$} & \multicolumn{3}{|l|}{$S G$} & \multirow[b]{2}{*}{$p^{*}$} \\
\hline & $\mathrm{n}$ & mean & SD & $\bar{n}$ & mean & SD & \\
\hline \multicolumn{8}{|l|}{ FFR Right ear } \\
\hline Latency I & 25 & 4.91 & 0.40 & 29 & 5.40 & 0.76 & $0.004^{*}$ \\
\hline Latency II & 25 & 6.58 & 0.62 & 29 & 7.31 & 0.91 & 0.001 \\
\hline Latency III & 25 & 8.40 & 0.88 & 29 & 9.25 & 1.10 & 0.003 \\
\hline Latency IV & 25 & 10.29 & 1.06 & 29 & 11.06 & 1.31 & 0.023 \\
\hline Latency V & 25 & 12.21 & 1.25 & 29 & 13.00 & 1.40 & 0.035 \\
\hline Latency VI & 25 & 14.08 & 1.28 & 29 & 15.10 & 1.61 & 0.014 \\
\hline Interpick I-II & 25 & 1.68 & 0.49 & 29 & 1.91 & 0.43 & 0.067 \\
\hline Interpick |I-III & 25 & 1.82 & 0.51 & 29 & 1.94 & 0.44 & 0.325 \\
\hline Interpick III-IV & 25 & 1.89 & 0.38 & 29 & 1.81 & 0.38 & 0.413 \\
\hline Interpick IV-V & 25 & 1.92 & 0.42 & 29 & 1.94 & 0.39 & 0.823 \\
\hline terp & 25 & 1.87 & 0.48 & 29 & 2.10 & 0.60 & 0.134 \\
\hline \multicolumn{8}{|l|}{ FFR Left ear } \\
\hline Latency I & 25 & 5.05 & 0.44 & 29 & 5.36 & 0.87 & $0.102^{*}$ \\
\hline Latency II & 25 & 6.66 & 0.70 & 29 & 7.36 & 0.99 & 0.004 \\
\hline Latency III & 25 & 8.32 & 0.94 & 29 & 9.20 & 1.11 & 0.003 \\
\hline Latency IV & 25 & 10.18 & 1.03 & 29 & 11.19 & 1.41 & 0.005 \\
\hline Latency V & 25 & 12.10 & 1.18 & 29 & 13.04 & 1.46 & 0.013 \\
\hline Latency VI & 25 & 14.00 & 1.36 & 29 & 15.11 & 1.73 & 0.012 \\
\hline Interpick I-II & 25 & 1.60 & 0.52 & 29 & 2.00 & 0.41 & 0.003 \\
\hline Interpick ||-||| & 25 & 1.67 & 0.51 & 29 & 1.84 & 0.41 & 0.165 \\
\hline Interpick III-IV & 25 & 1.86 & 0.36 & 29 & 1.99 & 0.59 & 0.357 \\
\hline Interpick IV-V & 25 & 1.91 & 0.41 & 29 & 1.85 & 0.36 & 0.545 \\
\hline Interpick V-VI & 25 & 1.90 & 0.43 & 29 & 2.07 & 0.45 & 0.158 \\
\hline
\end{tabular}

${ }^{*}$ t-Student test; ${ }^{*}$ equality of variance not assumed

FFR Frequency Following Response, CG Control group, SG Study group

indicates that the mechanism of vestibular migraine involves permanent alterations in subcortical auditory pathways.

The involvement of the brainstem and the diencephalon in migraines has been described [15], as has the involvement of the trigeminovascular system [16]. The relationship between these structures and the central and peripheral auditory systems has also been described $[17,18]$.

The frequency following response latencies were significantly longer in the patients with vestibular migraine than in the control group, suggesting altered pure tone temporal processing, which may also affect the processing of complex sounds. The topographic register of the frequency following response is the representation of the acoustic signal in cephalic regions of the brainstem, such as the inferior colliculus and lateral lemniscus [19-21]. These findings complement those of Agessi et al. [22], who reported worse outcomes for temporal resolution
Table $\mathbf{2}$ Loudness Discomfort Level means in the study and control groups

\begin{tabular}{|c|c|c|c|c|c|c|c|}
\hline & $C G$ & & & $S G$ & & & \\
\hline & $\bar{n}$ & mean & SD & $\bar{n}$ & mean & SD & $p^{*}$ \\
\hline $250 \mathrm{~Hz} R E$ & 16 & 104.06 & 7.12 & 16 & 95.94 & 8.41 & 0.006 \\
\hline $500 \mathrm{~Hz} R E$ & 20 & 107.50 & 9.67 & 18 & 98.33 & 11.88 & 0.013 \\
\hline $1000 \mathrm{~Hz} R E$ & 21 & 105.00 & 8.06 & 19 & 99.47 & 12.01 & $0.103^{*}$ \\
\hline $2000 \mathrm{~Hz} R E$ & 18 & 103.06 & 9.87 & 18 & 96.11 & 11.19 & 0.056 \\
\hline $3000 \mathrm{~Hz} R E$ & 19 & 104.21 & 10.04 & 19 & 95.53 & 12.46 & 0.023 \\
\hline $4000 \mathrm{~Hz} R E$ & 16 & 103.44 & 12.87 & 18 & 95.00 & 12.72 & 0.064 \\
\hline $6000 \mathrm{~Hz} R E$ & 10 & 99.50 & 12.79 & 15 & 95.33 & 12.32 & 0.423 \\
\hline $8000 \mathrm{~Hz} R E$ & 7 & 89.29 & 11.34 & 11 & 85.45 & 7.57 & 0.400 \\
\hline $250 \mathrm{~Hz} \mathrm{LE}$ & 13 & 98.46 & 8.99 & 16 & 92.81 & 10.48 & 0.136 \\
\hline $500 \mathrm{~Hz} L E$ & 21 & 106.43 & 11.08 & 19 & 97.63 & 11.83 & 0.020 \\
\hline $1000 \mathrm{~Hz} L E$ & 22 & 105.68 & 10.04 & 20 & 97.00 & 11.74 & 0.014 \\
\hline $2000 \mathrm{~Hz} L E$ & 20 & 105.25 & 11.41 & 18 & 95.28 & 11.18 & 0.010 \\
\hline $3000 \mathrm{~Hz}$ LE & 20 & 104.50 & 11.23 & 18 & 95.56 & 11.49 & 0.020 \\
\hline $4000 \mathrm{~Hz}$ LE & 15 & 101.67 & 11.90 & 18 & 96.39 & 13.15 & 0.240 \\
\hline $6000 \mathrm{~Hz} L E$ & 12 & 104.17 & 13.11 & 15 & 95.33 & 13.69 & 0.102 \\
\hline $8000 \mathrm{~Hz}$ LE & 7 & 87.86 & 12.54 & 10 & 85.50 & 11.41 & 0.693 \\
\hline
\end{tabular}

${ }^{*}$ t-Student test; ${ }^{*}$ equality of variance not assumed

CG Control group, SG Study group, RE Right ear, LE Left ear

during central auditory processing testing in migraine patients. The lack of similar studies of the frequency following response in vestibular migraine and migraine limits the literature comparison.

The lower discomfort thresholds suggest the presence of mild hyperacusis, in concordance with other previous studies. Sand and Vingen [23] and Sand et al. [24] hypothesized that this sound sensitivity could be related to subcortical disinhibition at the level of the activation nuclei, such as the inferior colliculus in the brainstem

Table 3 Classification of the Loudness Discomfort Level in the study group and control group

\begin{tabular}{|c|c|c|c|c|c|c|c|}
\hline & \multicolumn{2}{|l|}{$C G$} & \multicolumn{2}{|l|}{ SG } & \multirow[b]{2}{*}{$\mathrm{p}$} & \multicolumn{2}{|c|}{ Total } \\
\hline & $n$ & $(\%)$ & $n$ & $(\%)$ & & $n$ & $(\%)$ \\
\hline \multicolumn{8}{|l|}{ LDL RE } \\
\hline Negative level $^{a}$ & 18 & (81) & 10 & (47) & 0.019 & 28 & (65) \\
\hline Mild level ${ }^{b}$ & 4 & (18) & 11 & (52) & & 15 & (34) \\
\hline \multicolumn{8}{|l|}{$L D L L E$} \\
\hline Negative level $^{a}$ & 18 & (81) & 9 & $(45)$ & 0.039 & 27 & (64) \\
\hline Mild level ${ }^{b}$ & 4 & (18) & 10 & (50) & & 14 & (33) \\
\hline Moderate level $^{c}$ & 0 & $(0)$ & 1 & (5) & & 1 & (2) \\
\hline Total & 22 & (100) & 21 & (100) & & 43 & (100) \\
\hline
\end{tabular}

${ }^{\mathrm{a}}$ Discomfort level at $95 \mathrm{dBHL}$ or more; ${ }^{\mathrm{b}}$ discomfort level between 80 and 90 $\mathrm{dBHL}$ in two or more frequencies; 'discomfort level between 65 and $75 \mathrm{dBHL}$ in two or more frequencies

LDL Loudness Discomfort Level, CG Control group, SG Study group, RE Right ear, LE Left ear 
and the medial geniculate nucleus in the thalamus, reinforcing the hypothesis that migraine is triggered by a bottom-up mechanism, as other authors have also described [15, 25-28]. The relationship between low levels of serotonin in migraine and subcortical disinhibition, including that of the pontomesencephalic auditory pathways, in the inner ear and vestibular nuclei, has been demonstrated in previous studies [23, 28-30].

The remaining electrophysiologic tests did not show any significant difference, suggesting that binaural hearing, efferent auditory brainstem response suppression and auditory brainstem response are not altered in patients with vestibular migraine during the interictal period.

To date, there are no studies on the binaural interaction component in vestibular migraine or migraine. According to Shore et al. [18], the medial superior olivary complex, the main binaural interaction component structure, does not have any connection with the trigeminal ganglion, despite its anatomical proximity to structures supplied by the trigeminal nerve, such as the cochlear nucleus, lateral superior olivary complex and trapezoidal body. Additionally, Agessi et al. [22] did not find any disorder in the dichotic digits test of central auditory processing in patients with migraine; this test assesses figure-ground ability, which is based on binaural hearing. In concordance with these authors, the present study suggests that there are no abnormalities of binaural integration in patients with vestibular migraine.

Auditory brainstem response suppression with contralateral white noise in vestibular migraine did not yield any significant differences between the study group and the control group. This finding contrasts with other studies that used transient otoacoustic emission to evaluate contralateral suppression [6,31]. A possible reason is that the two tests involve different anatomical structures and analyze different responses: the outer hair cells and their otoacoustic emission are assessed in the contralateral suppression of transient otoacoustic emission [32], while the auditory nerve and auditory brainstem pathways and their electrical responses are assessed with efferent auditory brainstem response suppression.

As previous studies have suggested [33-35], there were no differences in auditory brainstem click responses between groups during the migraine interictal period. However, other authors found significant differences [36, 37]. These conflicting results could be related to the duration of the illness and the frequencies of migraine crisis [38]. The parameters used during the registration of auditory evoked potentials could also be related.

The contralateral acoustic reflex threshold analysis did not show a statistically significant difference between the two groups, most likely due to the small role of the tensor timpani muscle vs the stapedius muscle in triggering the acoustic reflex. The interneurons involved in tensor timpani muscle contraction receive descending impulses from the inferior colliculus, the superior olivary complex, serotoninergic sources and high cerebral centers. Although these areas are also involved in migraine and vestibular migraine, the participation of tensor timpani muscle contraction may not be strong enough to modify the acoustic reflex thresholds. The stapedius muscle does not have a direct anatomical relationship with vestibular migraine [39].

The auditory temporal processing brainstem disorder evidenced by the frequency following response and the mild hyperacusis observed in this study reinforce the hypothesis that the inferior colliculus has an important role in migraine and vestibular migraine pathophysiology. The inferior colliculus is part of the extralemniscal auditory pathway, a multisensorial system that is likely involved in the auditory symptoms of migraine. The neurons of the inferior colliculus dorsal nucleus connect to the auditory thalamocortical system. Connections between the inferior and the superior colliculus influence saccadic eye movements and other important motor responses to acoustic stimuli, which are essential for sound localization. The extralemniscal auditory system thus responds to both auditory and non-auditory stimuli, such as somatosensory, visual and vestibular stimuli. Auditory symptoms such as tinnitus, hyperacusis and discriminatory alterations could be related to the abnormal activation of this pathway [40].

The results of this study complement the knowledge that sensory input processing is abnormal in vestibular migraine and migraine $[23,27]$ and involves brainstem dysfunction. It also reinforces the established role of a bottom-up mechanism in the physiology of vestibular migraine [29]. More studies on the extension of migraine spectra are necessary to clarify the physiopathology and determine the involvement of all other sensory modalities, thus allowing the development of new treatment strategies.

Some limitations of this study are as follows: 1) the relatively small number of patients; 2) the cross-sectional design, which limits a longitudinal overview of the test results; and 3) the unknown duration of illness.

\section{Conclusions}

The current study suggested that temporal auditory processing and the loudness discomfort level are altered in vestibular migraine patients during the interictal period and may be used as diagnostic criteria.

\section{Abbreviations}

VM: Vestibular migraine

Acknowledgements

Not applicable. 


\section{Authors' contribution}

AAT enrolled patients, clinical followed them and drafted the manuscript. EHZ translated to English and got theoretical support. FFG and MLF revised and got theoretical support to the study. All authors read and approved the final version.

\section{Funding}

Not applicable.

\section{Availability of data and materials}

The datasets used and analyzed during the current study are available from the corresponding author on reasonable request.

\section{Ethics approval and consent to participate}

The procedures used in this study were approved by the ethical committee of Federal University of São Paulo (Comitê de Ética em Pesquisa da Universidade Federal de São Paulo - (EP UNIFESP), number 43437015.2.0000.5505. All subjects in this study agreed and signed the informed consent form.

\section{Consent for publication}

Not applicable.

\section{Competing interests}

The authors declare that they have no competing interests.

\section{Author details}

'Departamento de Otorrinolaringologia e Cirurgia de Cabeça e Pescoço, Universidade Federal de São Paulo, São Paulo, Brazil. ${ }^{2}$ Divisão de Educação e Reabilitação dos Distúrbios da Comunicação (DERDIC), Pontíficia Universidade Catolica de São Paulo, São Paulo, Brazil. ${ }^{3}$ Audio-Vestibular Clinic, Vancouver, Canada.

\section{Received: 14 February 2019 Accepted: 17 June 2019}

Published online: 27 June 2019

\section{References}

1. Neuhauser $H$, Leopold M, von Brevern M, Arnold G, Lempert T. The interrelations of migraine, vertigo and migrainous vertigo. Neurology. 2001; 56(4):684-6.

2. Lempert T, Olesen J, Furman J, Waterston J, Seemungal B, Carey J, Bisdorff A, Versino M, Evers S, Newman-Toker D. Vestibular migraine: diagnostic criteria - consensus document of the Bárány society and the international headache society. J Vestib Res. 2012;22(4):167-72.

3. Furman JM, Marcus DA, Balaban CD. Vestibular migraine: clinical aspects and pathophysiology. Lancet Neurol. 2013;12(7):706-15.

4. Lee H, Whitman GT, Lim JG, Yi SD, Cho YW, Ying S, Baloh RW. Hearing symptoms in migrainous infarction. Arch Neurol. 2003;60(1):113-6.

5. Battista RA. Audiometric findings of patient with migraine-associated dizziness. Otol Neurootol. 2004;25(6):987-92.

6. Bolay H, Bayazit YA, Gündüz B, Ugur AK, Akcali D, Altunyay S, llica S, Babacan A. Sub-clinical dysfunction of cochlea and cohlear efferents in migraine: an otoacoustic study. Cephalalgia. 2008;28(4):309-17.

7. Neff B, Staab J, Eggers S, Carlson M, Schmitt W, Van Abel K, Worthington D, Beatty C, Driscoll C, Shepard N. Auditory and vestibular symptoms and chronic subjective dizziness in patients with Meniere's disease, vestibular migraine and Meniere's disease with concomitant vestibular migraine. Otol Neurotol. 2012:33(7):1235-44.

8. Lempert T. Vestibular Migraine. Semin Neurol. 2013;33(3):212-8.

9. Campos MI, Reis CJ. Reflexo do músculo do estapédio alterado em portadores de epilepsia com audição normal. Rev bras otorrinolaringol. 1989;55(1):5-10.

10. Carmel P, Star A. Acoustic and non acoustic factors modifying midlle ear muscle activity in waking cats. J Neuro-Oncol. 1963;26(4):598-616.

11. Nields JA, Fallon BA, Jastreboff PJ. Carbamazepine in the treatment of Lyme disease-induced Hyperacusis. J Neuropsychiatry Clin Neurosci. 1999;11(1):97-9.

12. Headache Classification Committee of the International Headache Society (IHS). The International Classification of Headache Disorders, 3rd edition. Cephalalgia. 2018;38:193-5.
13. Knobel KAB, Sanchez TG. Nível de desconforto para sensação de intensidade em indivíduos com audição normal. Pró-Fono R Atual Cient. 2006;18(1):31-40.

14. Goldstein B, Shulman A. Tinnitus - Hyperacusis and the loudness discomfort level test - a preliminary report. Int Tinnitus J. 1996;2:83-9.

15. Akerman S, Holland PR, Goadsby PJ. Diencephalic and brainstem mechanisms in migraine. Nat Rev Neurosci [Internet]. 2011;12(10):570-84.

16. Stankewitz A, Aderjan D, Eippert F, May A. Trigeminal nociceptive transmission in migraneurs predicts migraine attacks. J Neurosci. 2011;31(6):1937-43.

17. Vass Z, Shore SE, Nuttall a L, Miller JM. Direct evidence of trigeminal innervation of the cochlear blood vessels. Neuroscience. 1998;84(2):559-67.

18. Shore S, Vass Z, Wys N, Altschuler R. Trigeminal ganglion innervates the auditory brainstem. J Comp Neurol. 2000;419(3):271-85.

19. Moushegian G, Rupert AL, Stillman RD. Scalp-recorded early responses in man to frequencies in the speech range. Electroencephalogr Clin Neurophysiol. 1973;35(6):665-7

20. Du Y, Kong L, Wang Q, Wu X, Li L. Auditory frequency-following response: a neurophysiological measure for studying the "cocktail-party problem". Neurosci Biobehav Rev. 2011:35(10):2046-57.

21. Gockel HE, Krugliak A, Plack CJ, Carlyon RP. Specificity of the human frequency following response for carrier and modulation frequency assessed using adaptation. J Assoc Res Otolaryngol. 2015;16(6):747-62.

22. Agessi LM, Villa TR, Dias KZ, Carvalho D, Pereira LD. Central auditory processing and migraine: a controlled study. J Headache Pain [Internet]. 2014;15(1):72.

23. Sand T, Vingen JV. Visual, long-latency auditory and brainstem auditory evoked potentials in migraine: relation to pattern size, stimulus intensity, sound and light discomfort thresholds and pre-attack state. Cephalalgia. 2000;20(9):804-20.

24. Sand T, Zhitniy N, White LR, Stovner $L$. Brainstem auditory-evoked potential habituation and intensity-dependence related to serotonin metabolism in migraine: a longitudinal study. Clin Neurophysiol. 2008;119(5):1190-200.

25. Lance JW, Lambert GA, Goadsby PJ, Duckworth JW. Brainstem influences on the cephalic circulation: experimental data from cat and monkey of relevance to the mechanism of migraine. Headache: The Journal of Head and Face Pain. 1983;23(6):258-65.

26. Weiller C, May A, Limmroth VA, Jüptner M, Kaube H, Kaube H, Schayck RV Coenen HH, Diener HC. Brainstem activation in spontaneous human migraine attacks. Nat Med. 1995;1(7):658-60.

27. Murdin L. Audiovestibular sensory processing in migraine. PhD [Thesis migrania] London. University College London, 2010.

28. Bhargava VK, McKean CM. Role of 5-hydroxytryptamine in the modulation of acoustic brainstem (far-field) potentials. Neuropharmacology. 1977;16(6):447-9.

29. Hamel E. Serotonin and migraine: biology and clinical implications. Cephalalgia. 2007;27(11):1295-300.

30. Marano E, Marcelli V, Di Stasio E, Bonuso S, Vacca G, Manganelli F, et al. Trigeminal stimulation elicits a peripheral vestibular imbalance in migraine patients. Headache. 2005;45(4):325-31.

31. Joffily L. de Melo Tavares de Lima MA, Vincent MB, Frota SMMC. Assessment of otoacoustic emission suppression in women with migraine and phonophobia. Neurol Sci. 2016:37(5):703-9.

32. Favero ML, Sanchez TG, Bento RF, Nascimento A. Contralateral suppression of otoacoustic emission in patients with tinnitus. Braz J Otorhinolaryngol. 2006;72(2):223-6.

33. Dash AK, Panda N, Khandelwal G, Lal V, Mann SS. Migraine and audiovestibular dysfunction: is there a correlation? Am J Otol Head Neck Med Surg. 2008;29(5):295-9.

34. Firat $Y$, Ozturan $O$, Bicak U, Yakinci C, Akarcay M. Auditory brainstem response in pediatric migraine: during the attack and asymptomatic period. Int J Pediatr Otorhinolaryngol. 2006;70(8):1431-8.

35. Arakaki X, Galbraith G, Pikov V, Fonteh AN, Harrington MG. Altered brainstem auditory evoked potentials in a rat central sensitization model are similar to those in migraine. Brain Res. 2014;1563:110-21.

36. Boyer N, Dallel R, Artola A, Monconduit L. General trigeminospinal central sensitization and impaired descending pain inhibitory controls contribute to migraine progression. PAIN ${ }^{\oplus}$. 2014;155(7):1196-205.

37. Hamed SA, Youssef AH, Elattar AM. Assessment of cochlear and auditory pathways in patients with migraine. Am J Otolaryngol. 2012:33(4):385-94.

38. Tessitore A, Russo A, Esposito F. Interictal cortical reorganization in episodic migraine without aurea: an event-related fMRI studying during parametric trigeminal nociceptive stimulation. Neurol Sci. 2011;32(Suppl1):S165-7. 
39. Mukerji S, Windsor AM, Lee DJ. Auditory brainstem circuits that mediate the middle ear muscle reflex. Trends Amplif. 2010;14(3):170-91.

40. Moller AR. Hearing: Anatomy, Phisiology and Disorders of the Auditory System. 2nd ed. Texas: Elsevier; 2006. p. 253-62.

\section{Publisher's Note}

Springer Nature remains neutral with regard to jurisdictional claims in published maps and institutional affiliations.

Ready to submit your research? Choose BMC and benefit from:

- fast, convenient online submission

- thorough peer review by experienced researchers in your field

- rapid publication on acceptance

- support for research data, including large and complex data types

- gold Open Access which fosters wider collaboration and increased citations

- maximum visibility for your research: over $100 \mathrm{M}$ website views per year

At $\mathrm{BMC}$, research is always in progress.

Learn more biomedcentral.com/submissions 